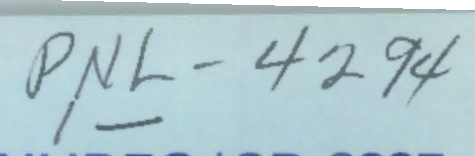

NUREG/CR-2835

PNL-4294

\title{
Review of Models Applicable to Accident Aerosols
}

Prepared by J. A. Glissmeyer

Pacific Northwest Laboratory

Operated by

Battelle Memorial Institute

Prepared for

U.S. Nuclear Regulatory

Commission 


\section{NOTICE}

This report was prepared as an account of work sponsored by an agency of the United States Government. Neither the United States Government nor any agency thereof, or any of their employees, makes any warranty, expressed or implied, or assumes any legal liability of responsibility for any third party's use, or the results of such use, of any information, apparatus, product or process disclosed in this report, or represents that its use by such third party would not infringe privately owned rights.

\section{Availability of Reference Materials Cited in NRC Publications}

Most documents cited in NRC publications will be available from one of the following sources:

1. The NRC Public Document Room, 1717 H Street, N.W. Washington, DC 20555

2. The NRC/GPO Sales Program, U.S. Nuclear Regulatory Commission, Washington, DC 20555

3. The National Technical Information Service, Springfield, VA 22161

Although the listing that follows represents the majority of documents cited in NRC publications, it is not intended to be exhaustive.

Referenced documents available for inspection and copying for a fee from the NRC Public Document Room include NRC correspondence and irternal NRC memoranda; NRC Office of Inspection and Enforcement bulletins, circulars, information notices, inspection and investigation notices; Licensee Event Reports; vendor reports and correspondence; Commission papers; and applicant and licensee documents and correspondence.

The following documents in the NUREG series are available for purchase from the NRC/GPO Sales Program: formal NRC staff and contractor reports, NAC-sponsored conference proceedings, and NRC booklets and brochures. Also available are Reguiatory Guides, NRC regulations in the Code of Federal Regulations, and Nuclear Regulatory Commission Issuances.

Documents available from the National Technical Information Service include NUREG series reports and technical reports prepared by other federal agencies and reports prepared by the Atomic Energy Commission, forerunner agency to the Nuclear Regulatory Commission.

Documents available from public and special technical libraries include all open literature items, such as books, journal and periodical articles, and transactions. Federal Register notices, federal and state legislation, and congressional reports can usually be obtained from these libraries.

Documents such as theses, dissertations, foreign reports and translations, and non-NRC conference proceedings are available for purchase from the organization sponsoring the publication cited.

Single copies of NRC draft reports are available free upon written request to the Division of Technical Information and Document Control, U.S. Nuclear Regulatory Commission, Washington, DC 20555.

Copies of industry codes and standards used in a substantive manner in the NRC regulatory process are maintained at the NRC Library, 7920 Norfolk Avenue, Bethesda, Maryland, and are available there for reference use by the public. Codes and standards are usually copyrighted and may be purchased from the originating organization or, if they are American National Standards, from the American National Standards Institute, 1430 Broadway, New York, NY 10018.

GPO Printed copy price: $\$ 3.75$ 
NUREG/CR-2835

PNL-4294

RZ

\section{Review of Models Applicable to Accident Aerosols}

Manuscript Completed: February 1983

Date Published: July 1983

Prepared by

J. A. Glissmeyer

Pacific Northwest Laboratory

Richland, WA 99352

Prepared for

Division of Risk Analysis

Office of Nuclear Reguletory Research

U.S. Nuclear Regulatory Commission

Weshington, D.C. 20555

NRC FIN B2287, B2407 



\section{ABSTRACT}

Estimations of potential airborne particle releases are essential in safety assessments of nuclear fuel facilities. This report is a review of aerosol behavior models that have potential applications for predicting aerosol characteristics in compartments containing accident-generated aerosol sources. Such characterization of the accident-generated aerosols is a necessary step toward estimating their eventual release in any accident scenario. Existing aerosol models can predict the size distribution, concentration, and composition of aerosols as they are acted on by ventilation, diffusion, gravity, coagulation and other phenomena. Models developed in the fields of fluid mechanics, indoor air pollution and nuclear reactor accidents are reviewed with this nuclear fuel facility application in mind. The various capabilities of modeling aerosol behavior are tabulated and discussed, and recommendations are made for applying the models to problems of differing complexity. 



\section{CONTENTS}

\begin{tabular}{|c|c|c|c|c|c|c|c|c|c|c|c|c|}
\hline ABSTRACT . & $\cdot$ & • & • & • & . & • & . & • & . & - & . & $i i i$ \\
\hline INTRODUCTIO & $0 N$ & - & - & $\cdot$ & - & - & • & . & • & - & 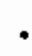 & 1 \\
\hline SUMMARY AND & D CONCLUS & IONS & . & . & ${ }^{*}$ & - & - & • & • & - & $\cdot$ & \\
\hline TRAJECTDRY & MODELS & - & - & - & 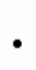 & - & $\bullet$ & 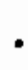 & 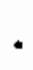 & - & " & \\
\hline INDOOR AIR & QUALITY & - & - & - & $\bullet$ & - & - & - & - & ${ }^{*}$ & 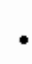 & \\
\hline NUCLEAR REA & ACTOR ACC & IDENT & & - & • & - & • & $\bullet$ & - & * & • & 10 \\
\hline BACKGR & ROUND. & - & . & - & • & - & • & • & • & $\bullet$ & " & 10 \\
\hline MODEL & CAPABILI & TIES & - & - & $\bullet^{\circ}$ & • & - & 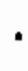 & $\bullet$ & 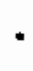 & 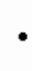 & 12 \\
\hline & Monodispe & rsed & . & - & - & - & • & " & - & $\bullet$ & * & 12 \\
\hline & Fixed Dis & tribut & tion & Type & $\cdot$ & - & • & & $\bullet$ & & 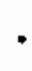 & 13 \\
\hline & Discrete & Distr & ibut & & $\bullet$ & . & • & • & • & & & 14 \\
\hline & Capabilit & y Mat & rix & - & $\cdot$ & - & - & $\bullet$ & - & $\bullet$ & $\bullet$ & 18 \\
\hline DEF INITIONS & * & - & - & - & • & - & $\bullet$ & $\bullet$ & • & • & $\bullet$ & 20 \\
\hline REFERENCES. & - & - & - & - & • & - & • & • & • & * & & Ref-I \\
\hline
\end{tabular}

\section{TABLES}

1. Modeling Applications . . . . . . . . . . . 4

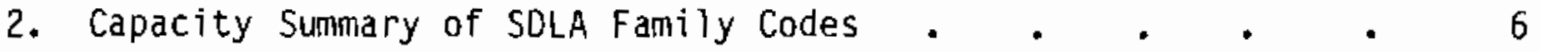

3. Capability Matrix of Published Reactor Aerosol Models . $\quad 19$ 



\section{INTRODUCTION}

In an accident where matter becomes airborne as small particles, several mechanisms come into play in describing the motion and fate of the particles. These include:

- particle size, shape and composition

- drag force

- diffusion

- thermophoresis

- electrical mobility

- settling due to gravity, electric fields or other body forces

- turbulent deposition

- agglomeration

- ventilation

- air cleaning.

Several widely available texts(a) address each of these mechanisms in detail (brief definitions of the more obscure terms are given on p. 21). It is the objective of this literature search to report on developments in combining the above mechanisms into models predicting aerosol behavior in compartments. In particular, we restrict our coverage to models which may be applicable to compartments typical of nuclear fuel plants, such as glove boxes, cells, drums, and rooms. Excluded from this study are models specific to complex ventilation systems, air cleaning devices, air sampling devices, and atmospheric dispersion that do not seem to fit the applications of interest. The models discussed here may range from a set of equations stated in the literature to fully-documented computer software.

The literature search found no aerosol models developed specifically for fuel cycle facilities. Instead, models including elements of aerosol behavior have been developing in four general groups over the past four decades:

- particle trajectory

- indoor air quality

- nuclear reactor accidents

- atmospheric dispersion.

Creation of the first group arose from a need for general fluid dynamics models to predict the flow field of liquid or gases in various geometries.

(a) Dallavalle (1943), Fuchs (1964), Mercer (1973), Dennis (1976), Hesketh (1977), and Friedlander (1977). 
These models have been extended to include the flow of particles and some limited gas/particle interactions. The second group was developed from recent concerns about the enhanced concentrations of combustion products, radon gas or other pollutants, as home and other structures become more airtight to improve fuel efficiency. The third group emerged from the need to predict the consequences of hypothetical nuclear reactor core accidents in terms of releases of radiotoxic gases and aerosols and their longevity in compartments. Finally, the last group was developed because of the need to predict the dispersion and transformation of pollutants in the atmosphere. Much of the theory used as a basis for the reactor accident aerosol models comes from the efforts of workers in the field of atmospheric aerosol dispersion, but it is taitored to the accident applications. The theory then finds embodiment in the well-documented and widely available reactor accident computer codes.

Workers in the field of atmospheric aerosol dispersion in simple and complex terrain have developed models similar in some respects to the particle trajectory models discussed in this review; however, the models are not configured for enclosed spaces. Therefore, this report will focus on the first three groups. If the need to model the behavior of aerosols extends beyond the capabilities of models in the first three categories, then the atmospheric aerosol modeling efforts should be investigated.

It is perhaps superficial to categorize the models discussed here in the terms mentioned above because all of the models of interest here are relevant to indoor air quality. However, the groupings reflect the genesis of the models, and it will be convenient to discuss them in that context. 
We have reviewed a large number of models and computer codes containing elements of aerosol dynamics in compartments. Taken as a whole, the various models have capabilities for almost any dynamic aerosol behavior mechanism. The problem lies in deciding how to apply available models to problems of accident-generated aerosols in compartments. The choice of modeling approach is dependent on the sophistication of the scenario and the information desired from the model.

For example, to model the dilution of gases or particles (ignoring deposition), it would be simplest to write the first-order ordinary differential equations to fit the situation in the manner employed in typical Indoor Air Pollution (IAP) models. If more than two compartments are modeled, then CORRAL may be more practical because it is designed to solve the differential equations for a large number of compartments simultaneously.

An example of a problem with extreme complexity would be a fire involving combustion product aerosols and an entrained radionuclide aerosol. If the modeler is interested in tracking the size distribution of the radionuclide as it interacts with the combustion products, then such a scenario would demand the capabilities of MSPEC, NAUA-4, or CONTAIN/MAEROS modified to consider two stratified zones.

The SOLA family of codes can have a wide area of application where aerosol concentration is low enough for coagulation to be insignificant. SOLA-3D has been used in applications where particles of more than one size were present. It does not seem likely, however, that a coagulation mechanism requiring a range of particle sizes could be modeled without including such a large number of particles that computation time would become a serious problem. The SOLAP and SOLA-3D codes could be very useful in determining the extent of aerosol mixing in a compartment and identifying areas where the compartment could be subdivided into well-mixed zones. SOLAP and SOLA-3D could assist in estimating the mass transfer rates between zones or compartments. SOLA-ICE may have applications where explosions or fires are to be considered.

Table 1 is an attempt to categorize different applications by level of sophistication and then to suggest a modeling approach. The applications are listed in order of cumulative complexity; in other words, the third application also includes the complexities of the first and second applications. It is apparent that more sophisticated codes like QUICK and CONTAIN/MAEROS could be made to fit the simplest application. However, it seems appropriate to use a modeling approach on the same level of sophistication as the application. 
TABLE 1. Modeling Applications

Applications in Order of Cumulative Complexity

1. Dilution of gases or non-depositing particles

2. Deposition of monodisperse particles by various mechanisms

3. Fixed particle size distribution with coagulation (with condensing vapors)

4. Time variant particle density, shape

5. Complex and arbitrary size distribution (with condensing vapors)

6. Multicomponent aerosol and chemical reaction
Modeling Approach

IAP, SOLA, CORRAL, PSI-CELL

IAP, SOLA-30, CORRAL, MAOCA, ETHERDEMO, PSI-CELL

SMOKLEAR, TRAP, HAA-3, (4) (TRAP-MELT)

HAARM -3

PARDISEKO-3, AEROSIM, CRAB, QUICK, ZONE, (NAUA-3)

CONTAIN/MAEROS, MSPEC, NAUA-4 
TRAJECTORY MODELS

In this section we will summarize the models used mostly for predicting the movement of individual particles in still or moving fluids. The state of the art in pre-computer-age models is represented by the work of Lapple and Shepherd (1940). They tabulated equations describing spherical particle trajectories in one or two dimensions in the presence of gravitational or centrifugal fields. The aerosol phenomena accounted for are frictional drag and settling. Their equations are applicable to a wide variety of systems where particles are larger than 1 um diameter and where slip is unimportant.

Many papers have been published concerning theory and computer models of fluid and particle flow in special configurations, e.g., flow around cylinders, plates, filter fibers, airfoils, and in channels, pipes, and aerodynamic particle sizing instruments. However, our interest is in models applicable to a variety of compartments. The Los Alamos National Laboratory developed several general-purpose and specialized fluid mechanics codes for modeling fluids and entrained particles in two- and three-dimensional spaces. The basic technique employed in the Los Alamos codes was developed by Welch et al. (1966) and called the "Marker-and-Cell" (MAC) technique. In this earliest form, the fluid was incompressible and viscous, could have free surfaces, and moved through a hypothetical two-dimensional space. The space was divided into rectangular cells where the contained fluid velocity was represented by vectors perpendicular to the cell surface. The Navier-Stokes and mass balance equations were solved on a cell-by-cell basis. A wave breaking over a dam or onto a beach provides a sample application of the method. The MAC method was later simplified somewhat by Amsden and Harlow (1970).

The MAC technique was soon applied to the three-dimensional flow of air and particles around structures in a series of papers by Hirt and Cook (1972), Hotchkiss and Hirt (1972) and Hotchkiss (1972). The structures modeled were 3-D rectangular parallelpipeds. Thermal buoyancy effects were included, and a technique developed by Sklarew (1970) was employed to represent convection and diffusion of particles. Sklarew's technique was to calculate the concentration gradient from the particle source using a diffusion coefficient and the convective velocity. Marker particles were then placed in each cell proportional to the caiculated trajectory of individual particles over finite time steps, accounting for Stokes' drag, gravity, and diffusion. Particle locations were updated with each time step. Special graphics techniques were deveroped to display velocity vectors, obstacles and particle locations (Hirt and Cook 1975). The complete documentation and listings for these codes were unpublished.

Following the above developments, Los Alamos developed a series of computer codes using a simplified MAC technique. The first of these, SOLA, was designed for users with little or no experience in numerical fluid mechanics. SOLA solves the Navier-Stokes equations in a two-dimensional plane. The hypothetical space modeled is rectangular and can be bounded by rigid walls with 1) free-slip or no-siip tangential velocities, and 2) inflow or outflow 
boundaries. Internal obstacles, fluid sources or sinks can be added by inserting special boundary conditions. The hypothetical space is subdivided into a computing mesh of equal rectangular cells in which fluid flow and mass balance computations are performed on a cell-by-cell basis. The code output is a tabulation of velocity vectors for each cell and each step in simulated time. Marker particles and particle dynamics were not included in the code. SOLA is documented in detail with code listings (Hirt, Nichols and Romero 1975). SOLA-SURF, an extension of SOLA, was developed to permit a free surface or curved rigid boundary to be located at the top or bottom of the fluid. This code was also fully documented by Hirt, Nichols and Romero (1975, 1976). SOLA-ICE, developed to permit the modeling of a compressible gas (Cloutman, Hirt and Romero 1976), is similar to SOLA in structure except that special equations for transfer of mass and internal energy, assuming an ideal gas, were added. Particle motion was not incorporated.

There have been several other extensions to the SOLA code for which full documentation is not available. Of greatest interest to this study are those versions which model particle dynamics and gas flow in two- and threedimensional spaces. SOLA, a code for computing velocity fields in a 2-D space, has been described above. SOLAP models the notion of particles within velocity fields developed with the SOLA code. The particle sources can be located anywhere in the SOLA computational mesh of cells. Stokes' drag, gravity settling and diffusion are the particle dynamics modeled. The motion of individual particles for finite time steps is tracked in the code. The application of the SOLA and SOLAP codes to problems of flow in a glove box was illustrated by Mitchell (1977). While documentation for the SOLAP code exists in-house, it has not been published formally.

The development of a 3-D fluid mechanics code, SOLA-30, was discussed by Hirt, Ramshaw and Stein (1977). Several versions of SOLA-30 were developed in-house by Los Alamos for applications to specific problems. Illustrations of the use of SOLA-3D in predicting airflows and particle motion in a glove box room were described by Scripsick et al. (1978) and Hirt, Stein and Scripsick (1978). In these applications, diffusion was the only aerosol behavior modeled. The SOLA-3D code has not yet been documented. The capabilities of the SOLA family codes discussed are summarized in Tabie 2 .

TABLE 2. Capability Summary of SOLA Family Codes

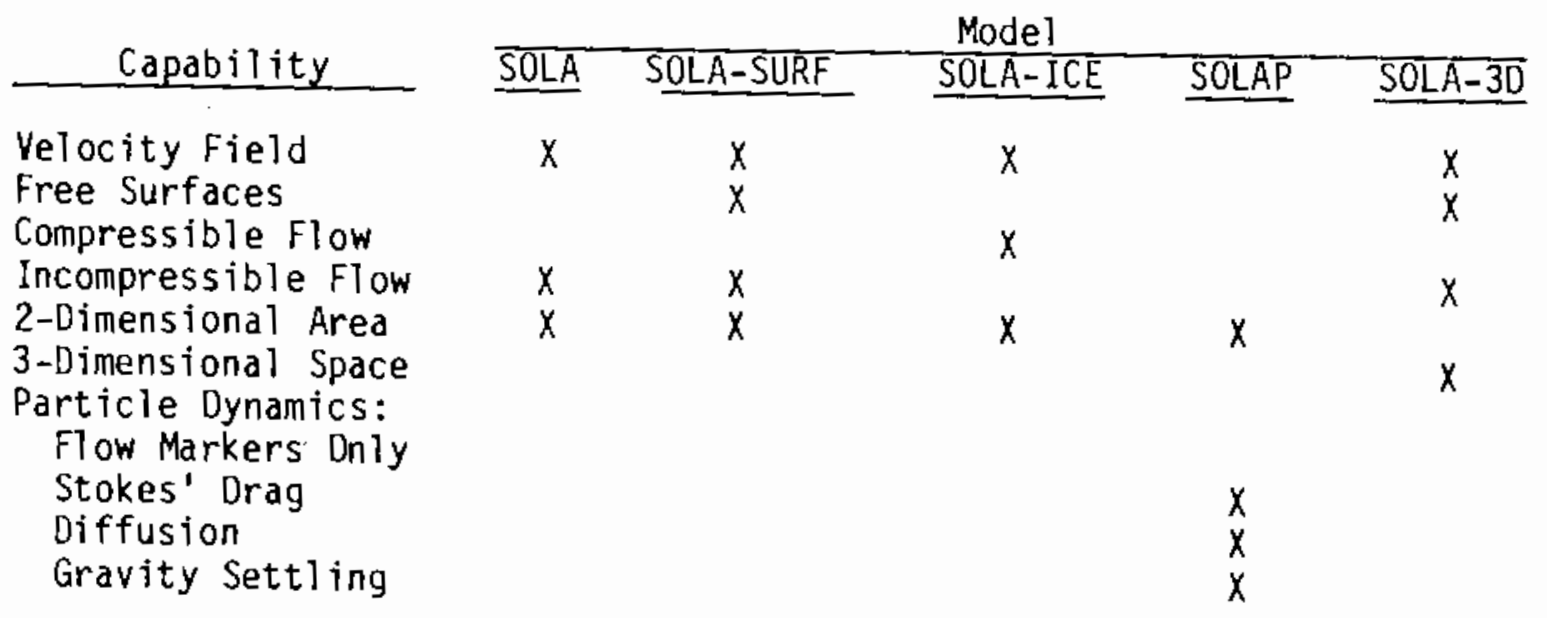


Another class of models where the trajectory of individual particles is calculated through a two-dimensional space subdivided into rectangular cells is that used for modeling gas-droplet flows. An example of this class of models is the Particle-Source-in-Cell (PSI-Cell) Model developed by Crowe, Sharama and Stock (1976). The basic concept is that as a droplet traverses a cell it may

- evaporate or condense, resulting in a mass source or sink to the gas phase

- accelerate or decelerate, resulting in momentum transfer between fluid and droplet

- conduct heat, resulting in a sink or source of thermal energy.

Thus, there is mass, momentum and thermal coupling between the droplet and gas phases. Besides the mass and energy transfer, the model accounts for Stokes" drag. The model is commonly used with droplet diameters on the order of hundreds of microns, as produced, for example, in spray cooling towers or ponds. With modifications, the capabilities could perhaps find application in these circumstances:

- flow of dry particles in air (the mass coupling equation could be removed)

- flow of uranium and plutonium compound solution drops in air.

Jurewicz (1977) modified the PSI-Cell model to include turbulent diffusion, gravity and electric field effects in calculating particle trajectory. These three effects were treated as body forces acting on the particles. To simplify the code, the mass and thermal gas-particle transfer terms were removed. The use of this version of PSI-Cell was illustrated by predicting velocities of $30 \mu \mathrm{m}$ glass particles perpendicular and parallel to the plates of an electrostatic precipitator. A study of this code should yield an estimated importance and a suggested method for including turbulent diffusion in predictions of the fate of accident-generated particles. 
Since the 1950's, researchers have been developing models for indoor air quality to aid in understanding and predicting pollutant concentration inside structures. There are several pollutants: steam from bathroom showers, tobacco smoke, radon, biological warfare aerosols, ozone, carbon monoxide, and other combustion products. The structures range from armored combat vehicles to restaurants to dwellings. The starting point of a model is an expression of mass balance for ventilation air and pollutant, such as that given by the Comrnittee on Indoor Pollutants (1981). For the air mass balance,

$$
q_{0}+q_{2}=q_{3}+q_{r}
$$

where $q$ is the volumetric flow rate for make-up air $\left(q_{0}\right)$, infiltration $\left(q_{2}\right)$, exfiltration $\left(q_{3}\right)$ and exhaust $\left(q_{r}\right)$. For the pollutant mass balance:

$$
v \frac{d C_{i}}{d t}=k q_{0} C_{0}\left(1-F_{0}\right)+k q_{1} C_{i}\left(1-F_{1}\right)+k q_{2} C_{0}-k\left(q_{1}+q_{3}+q_{r}\right) C_{i}+s-R
$$

\begin{tabular}{|c|c|c|c|}
\hline Make-up & $\begin{array}{l}\text { Recirculated } \\
\text { Return }\end{array}$ & $\begin{array}{l}\text { Infil- } \\
\text { tration }\end{array}$ & $\begin{array}{l}\text { Output due to } \\
\text { recirculation } \\
\text { feed, exfiltra- } \\
\text { tion, exhaust }\end{array}$ \\
\hline
\end{tabular}

where

$$
\begin{aligned}
C= & \text { concentration indoors }\left(C_{i}\right) \text { and outdoors }\left(C_{0}\right) \\
t= & \text { time } \\
q_{1}= & \text { flow rate of recirculation } \\
F= & \text { filter efficiency for makeup }\left(F_{0}\right) \text { and recirculation air }\left(F_{1}\right) \\
V= & \text { room volume } \\
S= & \text { indoor emission rate } \\
R= & \text { indoor sink removal rate including deposition and chemical } \\
& \text { transformation } \\
& \text { mixing factor (fraction of incoming air which completely mixes } \\
& \text { with indoor air). }
\end{aligned}
$$

The Comrnittee on Indoor Pollutants (1981) enumerates many applications of this approach. In most cases, simplifying assumptions are made, eliminating terms in the general equation. Equation (2) is repeated for each pollutant 
and each compartment, although frequently there is interest in just one pollutant and compartment. In this context, a compartment is defined in the Committee's report (1981) as a region within which spatial variations can be neglected over the time scale of interest. In compartments, the pollutants are taken to be well mixed, but the air exchange rate is modified by an empirical mixing factor.

Indoor air quality models do not generally contain complex particlesize-dependent aerosol removal mechanisms. Either aerosols are treated as gases, or the removal mechanisms are either simple first-order approximations or empirical. Sometimes time-dependent source terms are used, but most often only the solution to the steady-state case is of interest. Indoor air quality modelers generally report the equations used, but fully documented computer programs are not available. 


\section{NUCLEAR REACTOR ACCIDENTS}

Another major group of aerosol behavior models was developed for nuclear reactor safety studies. These models are mainly used for one or more large, well-mixed compartments. The size of these compartments is on the order of reactor containments and can be as large as $100,000 \mathrm{~m}^{3}$, although the data base for the models was obtained on volumes of $0.022-850 \mathrm{~m}^{3}$. Most of these models account for a wide variety of aerosol behaviors for the gross aerosol as a whole, while the trajectory models discussed above are concerned with individual particles. All of these models were written to describe aerosol behavior for a small number of well-defined accident scenarios; however, many of the models, in their entirety or in part, may have application to the types of accidents that occur in nuclear fuel facilities.

\section{BACKGROUND}

Elements of aerosol mechanics pertinent to the description of aerosol behavior in reactor accidents were drawn together by several authors (Oavis 1969; Castleman, Horn and Lindauer 1969; Koontz et al. 1970). They suggested that the following aerosol phenomena be considered in developing models of aerosol removal methods:

- Brownian coagulation

- turbulent coagulation

- gravitational coagulation

- gravity settling

- diffusion to the walls

- leakage or ventilation

- air cleaning.

Later modelers added many refinements and some additional removal methods such as thermophoretic deposition, turbulent deposition, and vapor condensation. Aerosol source modeling is done on an empirical basis. A large number of experiments were conducted on the generation of accident aerosols, and the results were used as inputs to the models.

Thorough summaries of model descriptions, theory, and experimental model verification have been prepared by Huang (1975) and by the Committee on the Safety on Nuclear Installations (CSNI 1979). Most of the models use the same general method of combining aerosol phenomena as is shown in Equation (3). 


$$
\begin{aligned}
\frac{\partial}{\partial t} n(x, t)= & 1 / 2 \int_{0}^{x}(\xi, x-\xi) n(\xi, t) n(x-\xi, t) d \xi \\
& -n(x, t) \int_{0}^{\infty}(x, \xi) n(\xi, t) d \xi \\
& -n(x, t) R(x)+S(x, t)
\end{aligned}
$$

where

$$
\begin{aligned}
(x, \xi)= & \text { the nornalized collision kernel predicting the probability } \\
& \text { of collision between two particles of volume } x \text { and ; collisions } \\
& \text { resulting from Brownian motion, gravitational settling, and } \\
& \text { turbulent gas motion } \\
x= & \frac{4}{3} \pi r_{1}^{3}=\text { volume of particle with radius } r_{1} \\
\xi= & \frac{4}{3} \pi r_{2}^{3}=\text { volume of particle with radius } r_{2} \\
t= & \text { time } \\
n(x, t)= & \text { the particle number distribution function } \\
R(x)= & \text { the removal rate of particles produced by gravitational } \\
& \text { settling to the floor, diffusion to the walls (wall plating), } \\
& \text { leakage, thermophoretic deposition, etc. } \\
\mathrm{S}(\mathrm{x}, \mathrm{t})= & \text { the source function rate of particles input to the vessel }
\end{aligned}
$$

The first integral represents the formation rate of particles with volumes between $x$ and $x+d x$ as the result of collisions of particles with volumes $\xi$ and $x-\xi$. The second integral represents the depletion of particles in the range of $x$ to $x+d x$ due to collisions with particles of all other sizes. The other two terms on the right are for the removal and addition of aerosols. Equation (3) is the framework on which most of the models include equations for agglomeration mechanisms, size distributions and depletion mechanisms.

Considerable experimental work has been done to investigate appropriate particle characteristics for use in many of these models. Much experimental effort is being made to verify model predictions for simulated accidents. The CSNI report (1979, p. 134) summarizes the types of aerosols which were used as a data base for many of these models. The aerosols consisted of mostiy uranium, plutonium, and sodium oxides with primary particle diameters in the range of 0.002 to 0.6 microns and geometric standard deviations from 1.35 to 2. Some of the same compounds may be airborne in a nuclear fuel cycle facility accident, but the particle size ranges may be significantly different. 
MODEL CAPAB ILITIES

The reactor accident aerosol models include a very wide range of capabilities. Due to the various accidents modeled, there are essentially three differences among them:

numerical solution techniques

assumed particle size distributions

particle depletion mechanisms.

For convenience in discussion, the models will be grouped by type of aerosol size distribution; i.e. monodispersed, fixed distribution, or discretized. Most of the codes are similar in that the particle inputs may include information on particle size distribution, particle characteristics, containment properties, thermal properties, concentrations, and quantities of particles and gases. Some codes will account for the fate of various chemical species. Most codes allow the user to vary with time the characteristics of input particles and vapors. The output of most codes gives as a function of time the amounts of airborne, deposited, or released contaminants and the size distribution of the aerosol.

\section{Monodispersed}

The models discussed here include those where the aerosol is considered to be either one size (monodispersed) throughout the entire simulated accident, or a single size that is reassigned periodically during the simulated accident.

Two hand calculation models developed by van de vate et a1. (1976) assume an instantaneous monodispersed aerosol source. MADCA was written to predict the depletion of particles by gravity settling while accounting for condensational particle growth. ETHERDEM0 calculates the depletion of particles caused by thermophoretic deposition. Both models could easily be incorporated as elements in larger models.

CORRAL (U.S. Nuclear Regulatory Commission 1975) predicts the transport and deposition of gaseous fission products and particles in containment systems of water-cooled reactors. CORRAL uses a monodispersed size distribution, but that size is changed with time by using an empirical equation with three constants. This method can then simulate the agglomeration observed or anticipated in experiments by choosing the constants to change the particle size. The particle deposition mechanisms include gravity settling, spray removal, and filtration. CORRAL has the capability for the simultaneous solution of large numbers of linear first-order ordinary differential equations. This allows the modeling of multicomponent pollutants in one or more compartments, assuming complete mixing in each compartment. With modifications, CORRAL has been applied to typical indoor air quality problems where there are several pollutants and compartments. CORRAL, MADCA and ETHERDEMO employ mass 
balance equations similar to Equations (1) and(2) and are more closely ailied to the indoor air quality approach than the approach employed in the other reactor accident codes to be discussed.

The last monodispersed particle code is TRAP BWR/PWR, which was developed by Gieske et a1. (1977) to model fission product transport in the primary containment systems of BWR/PWR reactors following a loss of coolant accident. The primary containment systems include the reactor core, plenum, pipes, heat exchanger, and other components. The code is primarily concerned with the two-phase flow, evaporation and condensation of liquids and gases; however, the deposition of particles in turbulent flow is included. The code was designed to provide input data for other codes which model transport in other containment volumes. This code will probably not have significant application to the failed-compartment accidents of interest here, because the aerosol behavior modeled is limited to turbulent deposition in pipes.

Fixed Distribution Type

The remaining reactor codes include time-dependent source particle size distributions and account for the effects of changing size distribution on depletion. The codes discussed here involve particle size distributions of one type throughout the simulated accident. The simplest of these codes, SMOKLEAR (Adams, Davis and Gill 1970; Davis 1971), utilizes a power law distribution where the number concentration is related to particle volume as

$$
\frac{d n}{d V}=\frac{A}{V^{2}}
$$

and

$$
A=\frac{1}{\frac{1}{V_{\min }}-\frac{1}{V_{\max }}}
$$

where $V_{\text {min }}$ and $V_{\text {max }}$ are the minimum and maximum particle volumes in the distribution. The Brownian coagulation of particles is accounted for, and the depletion mechanisms are thermophoresis and gravity settling.

There are many codes utilizing the assumption that the aerosol is lognormally distributed. One of the earliest of these is TRAP, developed by Castleman, Horn and Lindauer (1969), and Castleman (1969). The particle depletion mechanisms included are diffusion to the walls, gravity settling, and ventilation. The change in size distribution is accounted for by Brownian, gravitational and turbulent coagulation, as well as depletion.

Perhaps the most widely available of the reactor accidents codes is HAA-3 (Heterogenous Aerosol Agglomeration, Version 3) developed by several workers (Greenfield et al. 1969, 1970; Koontz et a1. 1970) and documented by Hubner, Vaughan, and Baurmash (1973). HAA-3 accounts for Brownian and gravitational 
agglomeration of particles, diffusion to the walls, and gravity settling. HAA-3 has been used as a basis for a series of modifications culminating in HAARM-3 (Heteorogeneous Aerosol Agglomeration Revised Model-3) documented by Gieseke, Lee and Reed (1978). (a) HAARM-3 was developed for more realistic simulation of LMFBR accidents through inclusion of more sophisticated aerosol mechanics; for example, thermophoretic deposition, dynamic shape factor, collision shape factor, turbulent agglomeration, and time-variant parameters such as temperature, pressure and particle-particle collision efficiency.

HAA-4A, under development at Atomics Internationa?(b), is similar to HAA-3 but has a rewritten numerical integration scheme to allow for higher initial concentrations (100,000 vs. 100 grams/cubic meter). In addition to the mechanisms of HAA-3, turbulent agglomeration, thermophoretic deposition, and vapor condensation on particles are included.

Another log-normal size distribution model is TRAP-MELT, developed by Jordan, Gjeseke and Baybutt (1979). TRAP-MELT is an extension of TRAP-BWR/PWR to model fission-product transport in the primary containment system following a core meltdown. The types of compartments considered are the same as in TRAP-BWR/PWR, but the atmosphere is superheated steam rather than saturated steam or two-phase liquid/gas. The aerosol dynamics modeled include Brownian and turbulent coagulation; vapor condensation on and evaporation from particles; and thermophoretic, gravity, diffusive and turbulent plateout mechanisms.

The last of the log-normal size distribution models to be discussed here is ABC-3, developed in Japan and described by Nishio, Kitani and Takada (1975). Most of the aerosol behavior mechanisms accounted for are the same as in HAARM-3, except that turbulent coagulation is not included. Also, there is no provision in $A B C-3$ for changing the apparent density of a particle with time or coagulation. The numerical solution technique is quite different from HAARM-3.

Discrete Distribution

The remaining reactor accident aerosol codes employ discretized particle size, which allows the use of size distributions more complex than log-normal. The particle size continuum is subdivided into a variable number of classes, each of which contains a fraction of the aerosol as input by the user. As particles change in size by some mechanism, they move from one class to another.

(a) The development of HARRM-3 is traced in reports by Reed and Gieseke (1975); Lee, Gieseke and Reed (1978); Gieseke, Jordan and Lee (1979a); Gieseke, Lee and Jordan (1979b); Gieseke, Lee and Jordan and Reed (1979); and Jordan, Schumacher, Lee, and Gieseke (1979). These references also document a thorough sensitivity analysis of HAARM-3.

(b) Communication between J. Glissmeyer, PNL, and J. Otter, Atomics Internationa T, on April 13, 1982 on the subject of HAA Code. 
Codes using the discretized size distribution include PARDISEKO-3b, NAUA-3, NAUA-4, AEROSIM, CRAB, QUICK, ZONE, MSPEC, AEROSOL and CONTAIN. This group generally addresses the same aerosol behavior mechanisms as the fixed size distribution codes. Three of the codes (MSPEC, NAUA-4, CONTAIN) are a significant departure because the user can input different size distributions for different chemical species. Except for ZONE, CONTAIN and NAUA-4, all of the codes discussed in this section are concerned with a single well-mixed compartment.

The PAROISEKO series of codes culminating in PARDISEKO-3, described by Jordan and Sack (1975), was developed in West Germany. It is probably the most widely available of the discretized size distribution codes. A detailed comparison of PARDISEKO-3b and HAARM-2 was made by Jordan (1975) and points out that outside of the solution technique there are only subtle differences in modeling some of the basic aerosol processes. PARDISEKO-3b, with an improved solution technique, uses 20 times less computing time than PARDISEK0-3 (CSNI 1979, P. 67). AEROSIM, described in the CSNI Report (1979) and by Walker, Kirby and Williams (1978), is similar to PARDISEKO-3 except for the numerical solution technique. Both AEROSIM and PARDISEK0-3b were developed for LMFBR accidents.

NAUA-3 was also developed in West Germany and was described by Haury and Schoeck (1976), Bunz and Schoek (197B), and Bunz, Koyro and Schoek (1981). While most of the aerosol mechanisms included are the same as described for other codes, NAUA-3 models LWR accidents. Therefore, it includes vapor condensation and evaporation from particles, in addition to the aerosol processes described under the previous two codes. For convenience, a log-normal function can be used to initialize the size channels.

MATADOR, under development at Battelle Memorial Institute (BMI), is a hybrid of the HAARM-3, CORRAL and discretized size distribution approaches in order to achieve a code that accounts for a variety of aerosol behaviors including agglomeration for up to ten connected compartments. Before running the code, the user will specify the aerosol mass associated with each of up to ten particle size bins. At each time step through the simutation, the code converts the discretized aerosol distribution into a log-normal distribution and uses a technique adapted from HAARM- 3 to account for agglomeration. That log-normal distribution is then converted back to the discretized distribution. The effects of gravity settling, diffusion, thermophoresis, diffusiophoresis, spray removal and engineered safety features are then calculated for each size bin using techniques developed for CORRAL. The code is currently in review status.

CRAB (Contained Radioactive Aerosol Behavior) was developed by BMI (Jordan, Gieseke and Schumacher 1979; Jordan, Suchmacher, Lee and Gieseke 1979; Jordan, Vaishnavi and Gieseke 1979) as a reference code against which more approximate codes (HAARM-3, PARDISEK0-3), requiring less computing time, could be tested. The idea was to arrive at a solution to Equation (3) using a finite difference approach to the size distribution, thus eliminating 
many simplifying assumptions required. for the HAARM-3 solution technique. The finite-difference approach is achieved by approximating the continuous distribution by straight line segments between size class boundaries.

Parallel with the work on CRAB, BMI developed QUICK, using different solution techniques which involve less computer time and resolve difficulties experienced with CRAB (Jordan, Schumacher and Gieseke 1981). The size distribution of the source aerosol is log-normal, and its parameters can vary with time. The input size distribution is discretized into channels which are then used throughout the code. The output tables are in the form of particle number and mass per size channe1. The QUICK code implements the same aerosol behavior mechanisms as HAARM-3 but uses more computer time to account for the discrete particle size classes.

Building on the solution techniques used in QUICK, BMI has developed a multi-compartment code (ZONE) and a multi-aerosol species code (MSPEC). ZONE models a long-term sodium fire where three concentration zones become established: the fire; the "chimney," or region where air rises above the fire; and the rest of the containment volume. The three zones are connected by convective flow. It was expected that aerosol concentration in the "chimney" zone was much higher than in the rest of the containment, so rapid particle growth would occur before particles were convected out of the "chimney" to regions closer to the walls. This concept is contrary to the usual assumption of homogeneous aerosol mixing. Testing of ZONE (Jordan, Schumacher, Gieseke, and Lee 1980) showed that, contrary to intuition, the spatial nonhomogeneity caused by the sodium fire did not significantly affect aerosol mass or size distribution at the walls as compared to a homogeneously mixed model (QUICK). The agreement between ZONE and QUICK predicted mass concentrations was within a factor of two, with the homogeneous case being equal or higher in concentration.

The multi-species aerosol code MSPEC is under development by Jordan, Schumacher and Gieseke (1982). MSPEC will accept as input the separate aerosol size distributions (log-normal or arbitrary) of different chemical species. The output allows one to plot the mass fractions and concentrations of each species versus particle size.(a) A motivation behind MSPEC arises from experiments showing that both fuel oxide and sodium oxide aerosols may be generated at different times in an LMFBR core accident. MSPEC is an adaption of QUICK and includes essentially the same aerosol behavior mechanisms. Tests

(a) Sample plots are found in Jordan, Schumacher and Gieseke (1982) and notes of the FY-1982 Fission Product Release and Transport Research Program MidYear Review, presented March 15, 1982. Contact: H. Jordan of Battelle Columbus Laboratories. 
with MSPEC indicated that the two types of aerosols generated in an experiment simulating the hypothetical LMFBR accident become homogeneous after two hours.

A soon-to-be pubiished code, CONTAIN (Sandia)(a), is different from the codes discussed in that it is an attempt to encompass many aspects of a reactor accident in addition to the aerosol behavior. The other aspects include melting fuel, boiling sodium, sodium and core reactions with concrete, and heat transfer. CONTAIN is set up to handle the interactions between several compartments and zones within compartments. The aerosol behavior module of CONTAIN is called MAEROS (Muiti-Component Aerosol Systems); its theory has been described by Gelbard and Seinfeld (1980) and Gelbard, Tambour and Seinfield (1980). MAEROS, which can be used as a stand-alone code for aerosol behavior, tracks the mass of more than one species through particle/gas, particle/particle, particle/surface, and gas/gas interactions.

Like MSPEC, MAEROS will accept and output separate size distributions for each aerosol species; however, the solution approach and technique are entirely different from MSPEC. MAEROS can be used as a generalized solution technique in which the user can incorporate the particle depletion mechanisms desired. Gelbard and Seinfeld (1980) have given examples where MAEROS was used to model Brownian coagulation, evaporation, and condensation on three aerosol species. CONTAIN does incorporate the same types of aerosol behavior common to many of the codes discussed earlier. AEROSOL (Gelbard 1981) is an earlier form of the theory included in MAEROS, but the solution technique did not track the distribution of various chemical species with respect to particle size. AEROSOL modeled Brownian coagulation, gravity settling, and condensational growth of particles.

NAUA-4 is another as yet unpublished code that models multiple aerosol species. (b) NAUA-4 is similar in most other respects to NAUA-3, except that two log-normal size distributions can be defined as source terms at any point in modeled time. Multiple chemical species can be identified by any fraction of either distribution. A subroutine then fills the discrete particle size channels with the appropriate number of particles from both distributions. Chemical species occurring in a given size channel are then assumed to be homogeneously distributed on all particles in that channel. As with most of the

(a) M. E. Senglaub, J. P. Odom, M. J. Clauser, J. E. Kelly, and P. C. Pickard. 1981. CONTAIN, A Computer Code for the Analysis of Containment Response to Reactor Accidents. DRAFT, Sandia National Laboratory, Albuquerque, New Mexico.

(b) H. Bunz, M. Koyro and W. Schoeck. NAUA MOD 4, A Code for Calculating Aerosol Behavior in LWR Core Melt Accidents, Code Description and Users Manual, DRAFT, Laboratory for Aerosol Physics and Filter Technique, NucTear Safety Project, Nuclear Research Center, Karlsruhe, Federal Republic of Germany. 
other codes, the input source size distribution can be varied with time or input as puffs. The code output gives size distribution data for the combined aerosol and the quantities of each chemical species airborne, deposited, or leaked out of the system.

\section{Capability Matrix}

Table 4 is a summary matrix of the published capabilities of aerosol modeling codes developed for reactor accidents. $01 d e r$ codes are often being updated to fit new data or new scenarios. The table is not meant to be the last word on capabilities; some of the older codes exist in many versions, and many new codes are unpublished as yet. However, Table 4 should help in selecting an approach to modeling aerosols in situations of interest to this study. Also of help will be the comparisons of some of the reactor accident codes given by Huang (1975), Jordan (1975) and CSNI (1979). 
IABLE 3. Capability Matrix of Published Reactor Aerosol Models

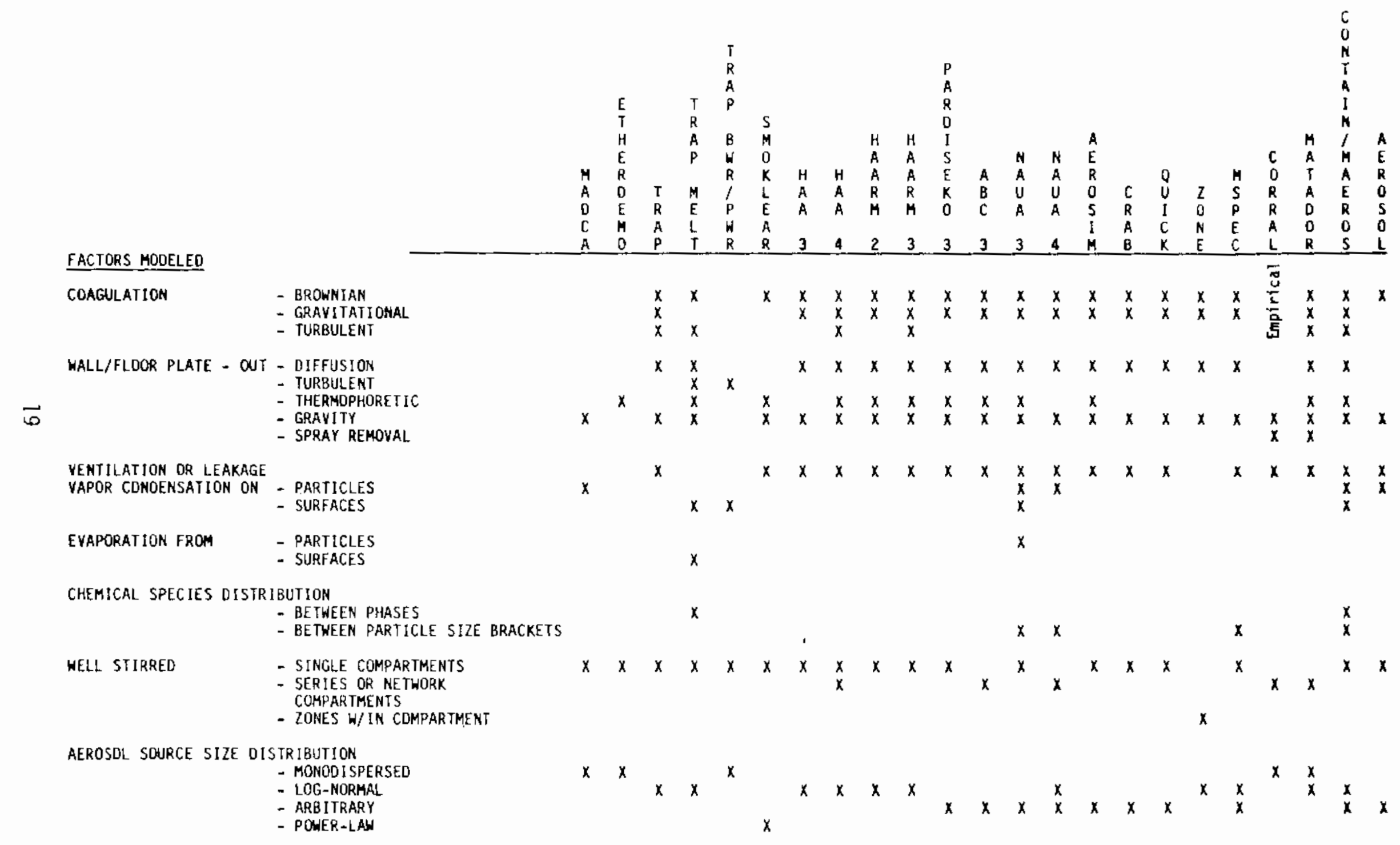




\section{DEFINITIONS}

Agglomeration - the irreversible combination or coagulation of particles

Diffusion - the net particle transport due to the random motion of particles from high to low regions of concentration.

Diffusiophoresis - the motion of particles, caused by their bombardment from a preferred direction by diffusing molecules in a non-uniform atmosphere such as water or sodium vapor condensing on a surface

Electrical mobility - the ratio of migration velocity to electric field strength for particles in an electric field

Thermophoresis - the motion of particles, due to a gas temperature gradient from high- to low-temperature regions or high-temperature gas to low-temperature surfaces

Turbulent deposition - deposition caused by particles which are unable to follow the eddy motion of the gas and are projected to a surface through the relatively quiescent gas near the surface 


\section{REFERENCES}

Adams, R. E., R. J. Davis and J. S. Gill. 1970. "Removal of Sol id Aerosol Particles." In ORNL Nuclear Safety Research and Development Program, Bimonthly Report, Jan-Feb 1970. pp.47-51, ORNL-TM-2919, Oak Ridge National Laboratory, Oak Ridge, Tennessee.

Amsden, A. A. and F.H. Harlow. 1970. The SMAC Method: A Numerical Technique for Calculating Incompressible Fluid Flows. LA-4370, Los Alamos National Laboratory, Los Alamos, New Mexico.

Bunz, H., M. Koyro and W. Schoeck. 1981. NAUA-MOD-3, A Computer Program for the Description of the Aerosol Behavior in a Condensing Atmosphere. KFK 3154, Nuclear Safety Project, Nuclear Research Center, Karlsruhe, Germany.

Bunz, H. and W. Schoeck. 1978. "Reduction of Released Fission Products in PWR Containments (NAUA Code)." In Proc. of Mtg. of the Projekt Nuklear Sicherheit, Karlsruhe, Germany. IN KA-CONF-78-078-007, Karlsruhe, Germany.

Castleman, A. W., Jr. 1969. A Summary of Recent Progress in Aerosol Research at Brookhaven National Laboratory. BNL-14271, Brookhaven National Laboratory, Brookhaven, New York.

Castleman, A. W., F. L. Horn and G. C. Lindauer. 1969. On the Behavior of Aerosols Under Fast Reactor Conditions. BNL-14070, Brookhaven National Laboratory, Brookhaven, New York.

Cloutman, L. D., C. W. Hirt and N. C. Romero. 1976. SOLA-ICE: A Numerical Solution Algorithm for Transient Compressible Fluid Flows. LA-6236, Los Alamos National Laboratory, Los Alamos, New Mexico.

Comnittee on Indoor Pollutants. 1981. "Modeling of Indoor Air Quality." In Indoor Pollutants. Board on Toxicology and Environmental Health Hazards, Assembly of Life Sciences, National Research Council, National Academy Press, Washington, D.C.

Committee on the Safety of Nuclear Installations. 1979. Nuclear Aerosols in Reactor Safety. CSNI/SOAR No. 1, Nuclear Energy Agency, Drganization for Economic Cooperation and Development, Paris, France.

Crowe, C. T., M. P. Sharama and D. E. Stock. 1976. "The Particle Source in Cell (PSI-Cel1) Model for Gas Droplet Flows," ASME Pub. 75-WA/HI-25.

Dallavalle, J. M. 1943. Micrometritics. 2nd ed., Pitman Publishing Corporation, New York. 
Davis, R. J. 1969. A Nuclear Safety Particle Primer. ORNL-4337, Oak Ridge National Laboratory, Oak Ridge, Tennessee.

Davis, R. J. 197l. "A Simple Model for the Estimation of Aerosol Concentration in a Closed Vessel." J. of the American Industrial Hygiene Association. Sept. 1971. pp. $603 \overline{-609}$.

Davis, R. J. and J. S. Gill. 1970. Estimation of Aerosol concentration in a Nuclear Containment After an Accident. 11th AEC Air Cleaning Conference, Richland, Washington. Aug-Sep, 1970, eds. M. W. First and J. M. Morgan, pp. 72-101, CONF 700816 .

Dennis, R., ed, 1976. Handbook on Aerosols. TID-26608, U.S. Energy and Research Development Administration, Washington, D.C.

Friedlander, K. S. 1977. Smoke, Dust and Haze, Fundamentals of Aerosols Behavior. John Wiley a Sons, New York.

Fuchs, N. A. 1964. The Mechanics of Aerosols. The MacMillan Company, New York.

Gelbard, F. 1981. AEROSOL Users Manual. NUREG/CR-1367, SAND80-0403, Sandia National Laboratories, Albuquerque, New Mexico.

Gelbard, F., and J. H. Seinfeld. 1980. "Simulation of Multicomponent Aerosol Oynamics. J. of Colloid and Interface Science. 78(2):485-501.

Gelbard, J., Y. Tambour and J.H. Seinfeld. 1980. "Sectional Representations for Simulating Aerosol Dynamics." J. of Colloid and Interface Science. $76(21) 541-556$.

Gieseke, J. A., et al. 1977. Analysis of Fission Product Transport Under Teminated LOCA Conditions, BMI-NUREG-1990, Battelle Memorial Institute, Columbus, ohio.

Gieseke, J. A., H. Jordan and K. W. Lee. 1979a. Aerosol Measurements and Modeling for Fast Reactor Safety, Quarterly Progress Report, Jan. 1-March 31, 1979. NUREG/CR-1165, BMI-2037, Battelle Memorial Institute, Columbus, Ohio.

Gieseke, J. A., K. W. Lee and H. Jordan. 1979b. Aerosol Measurements and Modeling for Fast Reactor Safety, Quarterly Progress Report, OctoberDecember 1978. NUREG-CR-1084, BMI-2024, Battelle Memorial Institute, Columbus, Ohio.

Gieseke, J. A., K. H. t.ee, H. Jordan and L. D. Reed 1979. Aerosol Measurements and Modeling for Fast Reactor Safety, Annual Report for FY-1978. NUREG-CR-0676, BMI-2021, Battelle Memorial Institute, Columbus, Ohio. 
Gieseke, J. A., K. W. Lee, and L. D. Reed. 1978. HAARM-3 User's Manual, BMI-NUREG-1991, Battelle Memorial Institute, Col umbus, Ohio.

Greenfield, M. A., R. L. Koontz and D. H. Hausknecht. 1969. Comparisons of Experiments with a General Equation for the Coagulation of Heterogenous Aerosols. Vol. II of Characteristics of Aerosols Produced by Sodium Fires. AI-AEC 12878, Atomics International.

Greenfield, M. A., R. L. Koontz and H. Morewitz. 1970. "Comparisons of Aerosol Experiments with a Model used in Reactor Siting Evaluation. In 11th AEC Air Cleaning Conference. August-September 1970, eds. M. W. First and J. M. Morgan, pp. 26-48 CONF 700816, Richland, Washington.

Haury, G., and W. Schoeck. 1976. "The Removal of Radioactive Aerosols from the Post-Accident Atmosphere of an LWR-Containment." In 14th ERDA Air Cleaning Conference, ed. M. W. First, pp. 737-748 CoNF-760822, Sun VaTley, Idaho.

Hesketh, H. H. 1977. Fine Particles in Gaseous Media. Ann Arbor Science, Ann Arbor, Michigan.

Hirt, C. W., and J. L. Cook. 1972. "Calculating Three-D Flows Around Structures and Over Rough Terrain." J. of Computational Physics, 10:324-340.

Hirt, C. W., and J. W. Cook. 1975. "Perspective Displays for Three Dimensional Finite Difference Calculations." Computers and Fluids, 3:293-303.

Hirt, C. W., B. B. Nichols and N. C. Romero. 1975. SOLA - A Numerical Solution Algorithrn for Transient Fluid Flows. LA-5852, Los Alamos National Laboratory, Los Alamos, New Mexico.

Hirt, C. W., B. B. Nichols and N. C. Romero. 1976. SOLA - A Numerical Solution Algorithm for Transient Fluid Flows - Addendum. LA-5852, Add., Los Alamos National Laboratory, Los Alamos, New Mexico.

Hirt, C. W., J. D. Ramshaw and L. R. Stein. 1977. Numerical Simulation of Three Dimensional Flow Past Bluff Bodies. LA-UR-7 7-1420, Los Alamos National Laboratory, Los Alamos, New Mexico.

Hirt, C. W., L. R. Stein and R. C. Scripsick. 1978. Prediction of Air Flow Patterns in Ventilated Rooms. LA-UR-791550, Los Alamos National Laboratory, Los Alamos, New Mexico.

Hotchkiss, R. S. 1972. "The Numerical Calculation of Three Dimensional Flows of Air and Particulates About Structures." Proc. of Symposium on Air Pollution, Turbulence and Diffusion, December 7-10,1971, eds. Church and Luna. pp. 35-42 CONF-711210. 
Hotchkiss, R. S., and C. W. Hirt. 1972. "Particulate Transport in Highly Distorted Three-Dimensional Flow Fields." LA-CD-72-365, Presented at and included in CONF-720615-1, Los Alamos National Laboratory, Los Alamos, New Mexico.

Huang, T. C. 1975. Review of Existing Aerosol Behavior Codes and Experimental Support. Presented at the Safety Technology Meeting on Radiological Consequence Assessment, July 30-31, 1975, General Electric Co., Canoga Park, California.

Hubner, R. S., E. V. Vaughan and L. Baurmash. 1973. HAA-3 User Report, AI-AEC-13038, Atomics International, Canoga Park, CaTifornia.

Jordan, H. 1975. A Comparison of HAARM-2 and PARDISEKD-III. BMI-X-667, Battelle Memorial Institute, Columbus, Ohio.

Jordan, H., J. A. Gieseke and P. Baybutt. 1979. TRAP-MELT User's Manual. NUREG/CR-D632, BMI-2017, Battelle MemoriaL Institute, Columbus, Ohjo.

Jordan, H., J. A. Gieseke and P. M. Schumacher. 1979. CRAB User's Manual. NUREG/CR-0872, Battel?e Memorial Institute, Columbus, 0hio.

Jordan, H., and C. Sack. 1975. PARIDISEKO-III: A Computer Code for Determining the Behavior of Contained Nuclear Aerosols. KFK 2151, Gesellschaft fur Kernforschung, Karlsruhe, Germany and UERFNR-1268, United States Uratom Fast Reactor Exchange Program.

Jordan, H., P. M. Schumacher and J. A. Gieseke. 1981. QUICK User's Manual. NUREG/CR-2105, BMI 2082, Battelle Memorial Institute, Columbus, Ohío.

Jordan, H., P. M. Schumacher and J. A. Gieseke. 1982. "Influence of Agglomerate Shape Factors on the Dynamics of a Two Component Aerosol--A Theoretical Investigation." Presented to 1st Annual American Association of Aerosol Researchers Meeting, Santa Monica, California, February 1982 (Abstract).

Jordan, H., P. M. Schumacher, J. A. Gieseke and K. W. Lee. 1980. Multiple Zone Aerosol Behavior Model. NUREG/CR-1294, BMI-2042, Battelle Memorial Institute, Columbus, Ohio.

Jordan, H., P. M. Schumacher, K. W. Lee, and J. A. Gieseke. 1979. Recent Results of Nuclear Aerosol Behavior Code Development." In Proceedings of International Meeting on Fast Reactor Safety Technology, August 12-13, 1979, Vol. II, TK/9142/I65/1979, p. 851. Seattle, Washington.

Jordan, H., B. Vaishnavi and J.A. Gieseke, 1979. The Numerical Method of the Aerosol Behavior Reference Code, CRAB. NUREG/CR-0620, BMI-2016, Battelle Memorial Institute, Columbus, Ohio. 
Jurewicz, J. T., 1977. "A Numerical Model for Turbulent Diffusion in GasParticle Flows." ASME Publication 76-WA/FE-33.

Koontz, R. L, L. Baurmash, M. A. Greenfield, C. T. Nel son, D. F. hausknecht, E.U. Vaughan, M. Silberburg and H. A. Horewitz. 1970. Aerosol Model ing of Hypothetical LMFBR Accidents. AI-AEC-12977, Atomics International, Canoga Park, California.

Lapple, C. E., and C. B. Shepherd. 1940. "CaTculation of Particle Trajectories." Industrial and Engineering Chemistry. 32(5) 605-617.

Lee, K. W., J. A. Gieseke and L. D. Reed. 1978. Sensitivity Analysis of the KAARM-3 CDode. NUREG-CR-0527, BMI-2008, Battelle Memorial Inst itute, Columbus, Ohjo.

Mercer, T. T. 1973. Aerosol Technology in Hazard Evaluation. Academic Press, New York.

Mitchell, D. H. 1977. Considerations in the Behavior of Aerosols in Glove Boxes. I. Models. BNWL-2382, Pacific Northwest Laboratory, Richtand, Washington.

Nishio, G., S. Kitani and J. Takada. 1975. "Evaluation of Plutonium 0xide Aerosol Release from an LMFBR in a hypothetical Accident." Nucl. Eng \& Dsgn, $34: 417-428$.

Reed, L. D., and J. A., Gieseke. 1975. HAARM-2 User's Manual. BMI-X-665, Battelle Memorial Institute, Columbus, 0 hio.

Scripsick, R.C., D. C. Gray, M. I. Tillery, R. G. Stafford and P. C. Romero. 1978. Aerosol Sampling and Characterization for Hazard Evaluation. LA-7537-PR, Los Alamos Nationa? Laboratory, Los Alamo, New Mexico.

Sklarew, R. C. 1970. "A New Approach: The Grid Model of Urban Air Pollution." Presented at the 63rd Annual Meeting of the Air Pollution Contro1 Association, June 14, 1970, St. Louis, Missouri.

United States Nuclear Regulatory Commission. 1975. Reactor Safety Study. WASH-1400, Washington, D.C.

Van de Vate, J. F., A. Plomp, C. De Jong and H. C. D. Smit. 1976. "Deposition of Aerosols Formed by HCDA Due to Heat Transport in LMFBR Inner Containment Atmospheres." In Proceedings of ANS/ENS Conference on Fast Reactor Safety, CDNF 761001, Chicago, Il]inois.

Walker, B. C., C. R. Kirby and R. J. Williams. 1978. Discretization and Integration of the Equation Governing Aerosol Behavior. SRD-R-98, United Kingdom Atomic Energy Authority. 
Welch, J. E., F.H. Harlow, J. P. Shannon and B. J. Daly, 1966. The MAC Method, A Computing Technique for Solving Viscous, Incompressible, Transient Fluid-Flow Problems Involving Free Surfaces. LA-3425, Los ATamos NationaT Laboratory, Los Alamos, New Mexico. 
NUREG/CR-2835

PNL-4294

RZ

\section{DISTRIBUTION}

No. of

Copies
No. of

Copies

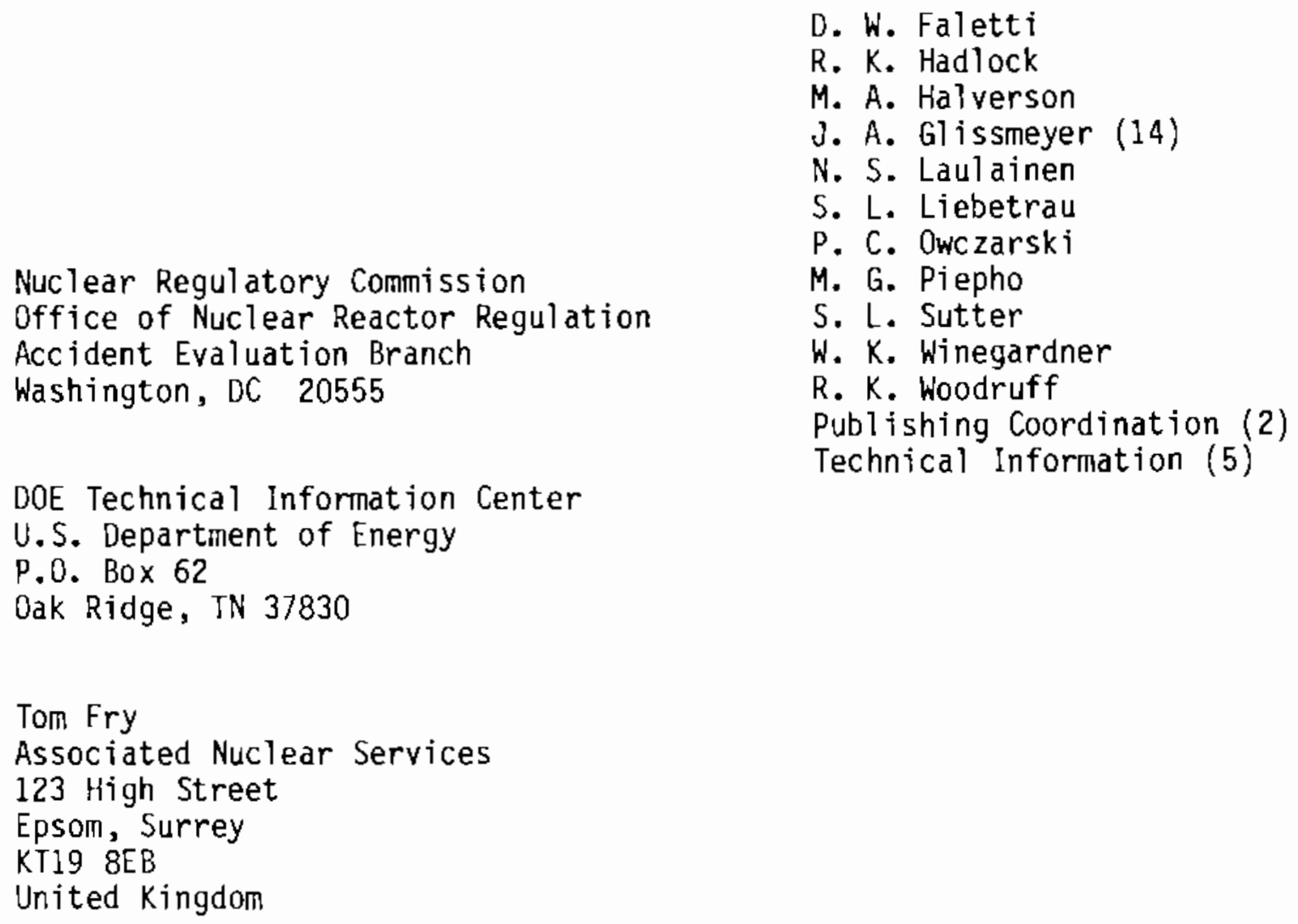

\section{ONSITE}

2 Hanford Engineering Development Laboratory

J. D. McCormack

A. K. Postma

Pacific Northwest Laboratory
G. F. Athey
C. E. Elderkin 



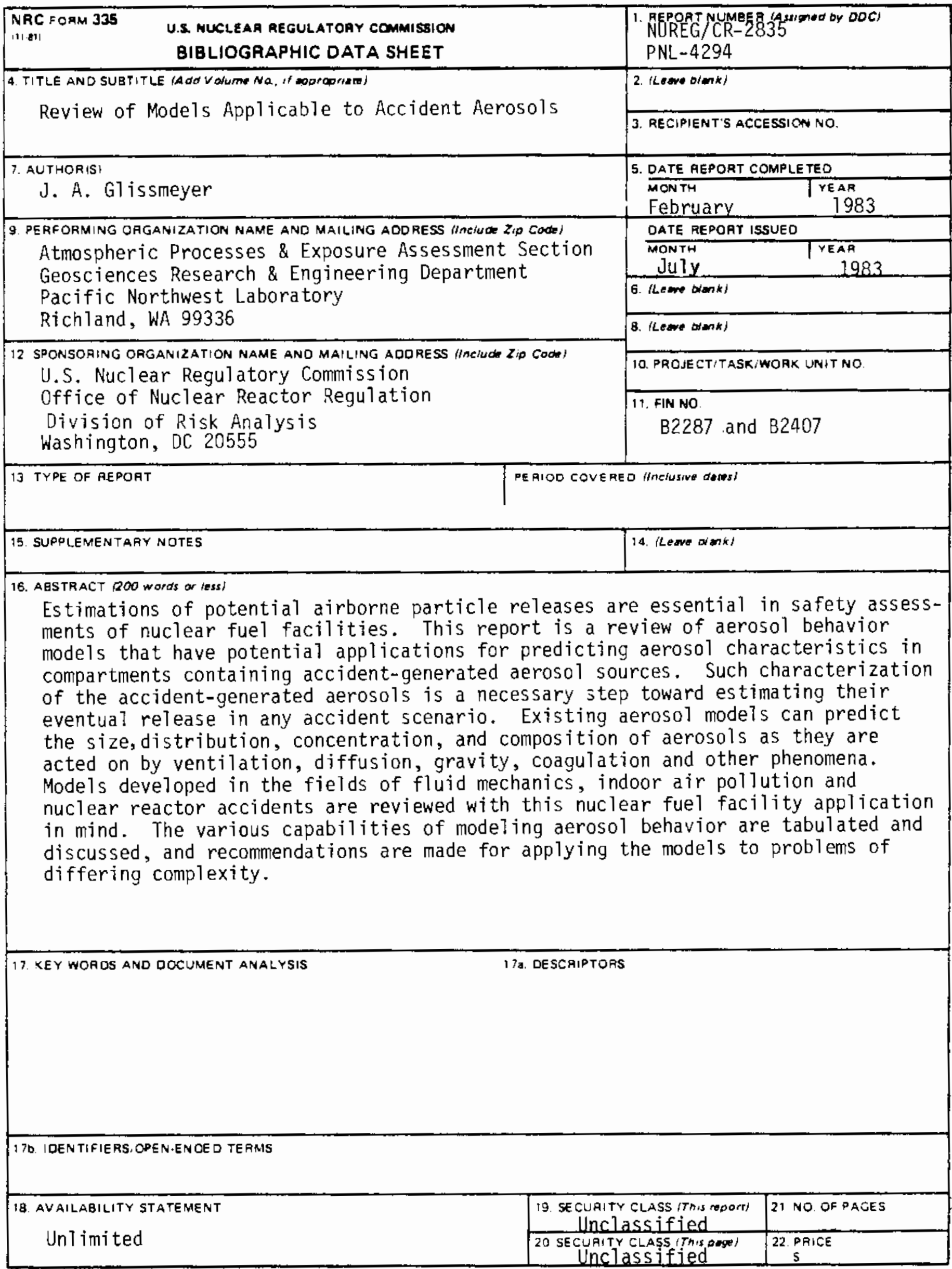


